\title{
Design of Vineyard Ecological Environment Monitoring System Based on Wireless Sensor Network
}

\author{
Zhenwei Song ${ }^{1}$, Rongjin Yang ${ }^{2}$, Qiao Song ${ }^{1}$, Meiying Sun ${ }^{1}$, Yi Zhang ${ }^{1}$, Xiuhong $\mathrm{Li}^{1+}$, Lu Liu $^{1}$ and \\ Yushuang $\mathrm{Ma}^{1}$ \\ ${ }^{1}$ State Key Laboratory of Remote Sensing Science, College of Global Change and Earth System Science, \\ Beijing Normal University, Beijing, China \\ ${ }^{2}$ Chinese Research Academy of Environmental Sciences, No.8, Da Yang Fang, An Wai, Chao Yang, Beijing \\ 100012, China; yangrj@craes.org.cn
}

\begin{abstract}
Grape growth is restricted by natural conditions such as soil, water and climate, At the same time, the artificial planting method of grape " buried in winter and dug out in spring " is pointed out to increase the concentration of particulate matter in the air. In order to meet the requirements of vineyard ecological environment monitoring, and solve these contradictions between the grape industry and environmental protection. This paper intends to design a vineyard ecological environment monitoring system based on wireless sensor network by using wireless sensor network technology. It monitors four influencing factors such as soil condition, meteorological condition, groundwater level and air quality. It realizes the real-time collection, transmission, display and storage of vineyard ecological environment data. The obtained data can provide support for the management and development of the vineyard industry.
\end{abstract}

Keywords: grape industry; wireless sensor network; ecological environmental monitoring.

\section{Introduction}

The grape producing area in the eastern foot of Helan Mountains is located in the golden latitude zone of world wine. Under the background of the slow development of world wine industry and the rapid development of China's wine industry, the grape industry in the eastern foot of Helan Mountains has developed rapidly. It shows that the area of grape planting and wine productivity, yield, quality and influence are rapidly improved ${ }^{[1]}$.Under the background of dealing with global problems such as climate change, ecological imbalance, environmental pollution and resource shortage, green transformation and low-carbon development have become a new trend of global sustainable development ${ }^{[2]}$. This will certainly have a profound impact on the realization of green economic transformation in this region. As a typical example of green development, wine industry fully embodies the concept of green, low carbon (negative carbon) and cyclic development, and is a breakthrough for this region to seek green economic transformation [1].

It is worth noting that the transformation from lucid waters and lush mountains to invaluable asset involves a key issue, which is the relationship between industrial development and environmental protection. The geographical environment of the grape-producing area in the eastern foot of Helan Mountains is unique. Although it has natural conditions suitable for grape growth, its ecological environment is also very fragile. Especially with the climate warming, frequent extreme climate events lead to frequent meteorological disasters of wine-making grapes, which seriously affects the healthy development of wine-making grapes in the eastern foot of Helan Mountains and affects the wine-making industry. The impact is becoming more and more obvious ${ }^{[3]}$. Moreover, some research have pointed out that the cultivation method of wine grapes

Corresponding author. Tel.: +13621166693; fax: +010-58802190.

E-mail address: lixh@bnu.edu.cn. 
"buried in winter and dug out in spring" would increase the concentration of particulate matter in the atmosphere and pollute the air.

Wireless Sensor Networks (WSN), which has been developed in recent years, combines sensor technology, embedded technology, modern network and wireless communication technology, distributed information processing technology and so on. It can form a network by self-organization through randomly distributed micro-nodes integrated with sensors, data processing units and communication modules, and with the help of inside nodes. Various types of sensors can measure the temperature, humidity, noise, light intensity, pressure, soil composition and other information in the surrounding environment. They can realize real-time data transmission through short-distance wireless low-power communication technology (such as "WiFi", "Bluetooth", "ZigBee"). They have broad application prospects ${ }^{[3]}$. This paper propose to establish an ecological environment monitoring system based on wireless sensor network for vineyards in the eastern foot of Helan Mountains. It can monitor various ecological environment indicators, collect first-hand information, analyze the monitoring data, evaluate the advantages and disadvantages of current grape cultivation and management methods, and put forward the path of industrial adjustment and development combined with monitoring and evaluation.

\section{Survey of the research area}

This paper takes the vineyard at the eastern foot of Helan Mountains as the research area, as shown in Figure 1. The eastern foot of Helan Mountains is located in $37^{\circ} 43^{\prime} 00^{\prime \prime}-39^{\circ} 05^{\prime} 3^{\prime \prime} \mathrm{N}, 105^{\circ} 45^{\prime} 39^{\prime \prime}-106^{\circ} 27^{\prime} 35^{\prime \prime}$ $\mathrm{E}$, which is the "golden zone" of world grape cultivation. The eastern foot of Helan Mountains is located in the temperate continental arid and semi-arid climate zone, it belongs to the typical continental climate. The area has abundant solar energy resources, long sunshine time and large temperature difference between day and night. The annual sunshine hours are 2851-3106 hours, the annual average effective accumulated temperature (> 10 degrees $\mathrm{C}$ ) is 1534.9 degrees $\mathrm{C}$, the effective accumulated temperature is 961.6 degrees $\mathrm{C}$ from July to September, and the annual precipitation is $193.4 \mathrm{~mm}$. The eastern foot of Helan Mountains is a three-stage step of alluvial fan. The main source rock is alluvium. The terrain is small, flat, small and shallow ravines, and the soil erosion is mild. The grape-producing area in the eastern foot of Helan Mountains belongs to the important area of biodiversity conservation and wind-proof and sand-fixing in the national ecological function regionalization (revised edition) of the western Ordos-Helan Mountains-Yinshan Mountains, which has very important functions of water conservation and wind-proof and sand-fixing. It belongs to the main production area of Hetao Irrigation Area in the strategic pattern of agricultural planning in the main functional areas of the country, with excellent irrigation conditions and good conditions of light, hot water and gas. The unique geographical and climatic conditions make it one of the few regions in the world that can produce high-quality and high-end wines. The grape producing area in the eastern foot of Helan Mountains was designated as National Geographic Indicator Product Protected Area in 2002. The area can be used to grow grapes with land of over 100 million $\mathrm{m}^{2}$. It is the largest protected area for landmark geographical products of wine in China.

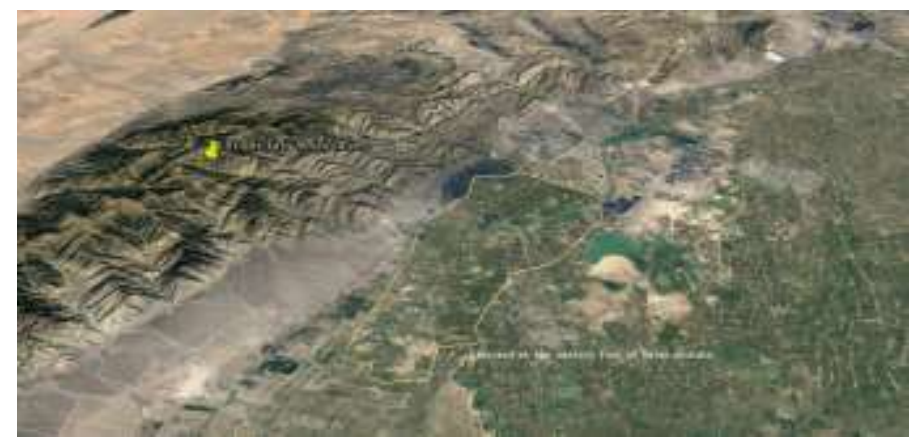

Fig 1: Satellite Remote Sensing Image of Vineyard in the Eastern Piedmont of Helan Mountains

\section{System design}

\subsection{Overall framework of the system}

This paper intends to use wireless transmission, network communication, computing model, feedback 
control, WEB publishing and mobile APP and other technical means to build an intelligent vineyard ecological monitoring system. According to the actual needs of vineyard ecological monitoring in the eastern foot of Helan Mountains, the observation indicators are determined by rational planning, so that the monitoring system can acquire real-time, continuous and effective data of key areas and objects of concern. The overall architecture of the system is shown in Figure 1. The system takes the data center as the center and receives the monitoring data of the acquisition equipment. Users can access the data center by using PC terminal and mobile phone through the publishing platform.

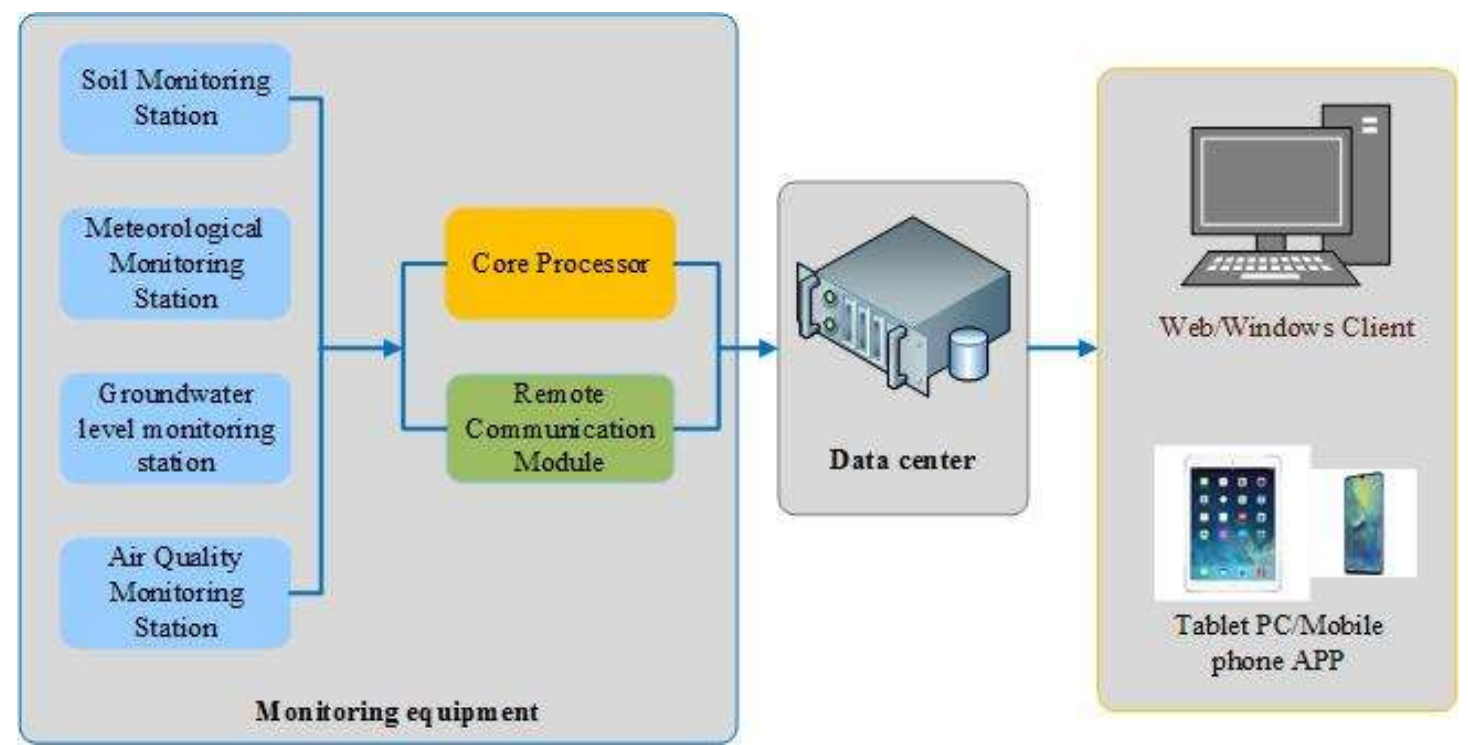

Fig. 2: System Structure Diagram

\subsection{Selection of indicators}

The quality of wine grape mainly depends on grape varieties and corresponding ecological conditions. Grape varieties can be changed through variety selection and introduction. The ecological conditions of a certain region are comprehensive manifestations of water, heat, light, temperature and other factors. It is relatively stable ${ }^{[5-7]}$. The factors such as air temperature and humidity, soil temperature and humidity, light intensity and carbon dioxide concentration in vineyard environment have an important impact on the growth and development of grapes, the prevention and control of diseases and insect pests, etc. It is pointed out that the planting mode of grape "buried in winter and dug out in spring" will increase the concentration of particulate matter in the air. In order to develop grape industry in a green and healthy way and build a wise vineyard, this paper propose to monitor the vineyard in the eastern foot of Helan Mountains from the following indicators.

(1)Soil monitoring

Soil is closely related to the fine quality of wines. The elegance and typical characteristics of wines are given by special soil conditions. Under the same climatic conditions, the effects of different soil chemical conditions on grape quality were quite different ${ }^{[8-9]}$. For example, the $\mathrm{pH}$ value of soil will affect the absorption of nutrients by grape plants, and the relationship between soil nutrient content and grape and wine quality is very close. In this paper, we select four indicators to monitor: the temperature, humidity, $\mathrm{pH}$ and organic matter of soil.

(2)Meteorological monitoring

The vineyards in the eastern foot of Helan Mountains are often located in the suburban farmland far from the city, and have their own unique farmland microclimate. There are many factors affecting the quality of wine grapes, such as meteorological conditions, soil, variety characteristics and cultivation techniques. Temperature, precipitation and air humidity play a decisive role in the growth, development, yield and quality formation of wine grapes ${ }^{[10-11]}$. Zhang Xiaoyu et al. ${ }^{[12]}$ showed that temperature played an important role in the formation of wine grape quality, light directly affected sugar accumulation and tannin synthesis, precipitation could indirectly affect field relative humidity and hydrothermal coefficient, as well as accumulated temperature and average temperature. In this paper, five meteorological factors, temperature, humidity, light, total radiation and rainfall, are selected to be monitored.

(3)Groundwater level monitoring

Grape has strong root system and is a drought-tolerant fruit tree. Its total water demand varies with the 
age, yield, competitive weeds and humidity of grape, and the water demand varies at different growth stages. Excessive water stress will affect the healthy growth of grape, resulting in a decline in the quality of grape products ${ }^{[13]}$. Water shortage is the most restrictive factor for the development of wine grape cultivation in the eastern foot of Helan Mountains. It is unsustainable to rely on groundwater as the water resources guarantee system for grape cultivation. Groundwater level monitoring can dynamically show the change of groundwater level and provide data basis for water diversion.

(4)Air quality monitoring

The healthy growth of grapes needs a good environment. Setting up monitoring points for particulate matter in the vineyard at the eastern foot of Helan Mountain is helpful to monitor the impact of cross-border pollution such as building dust and automobile exhaust on the vineyard at the eastern foot of Helan Mountain. Moreover, some people believe that the cultivation mode of "buried in winter and dug out in spring" will lead to air pollution (mainly referring to dust pollution caused by burying grapes and picking vines). The monitoring of particulate matter in the vineyards at the eastern foot of Helan Mountain can also confirm the correctness of this statement. In this paper, PM2.5, PM10, $\mathrm{O}_{3}, \mathrm{CO}, \mathrm{SO}_{2}, \mathrm{NO}_{2}$ and other factors that can reflect the concentration of particulate matter are selected for monitoring.

Selection of Collectors

(1)Soil Monitoring Station

Soil monitoring requires that the temperature and humidity of the surface soil of vineyard can be observed and recorded. This system uses Hydra soil moisture, temperature and electrical conductivity sensors produced by Beijing Zhirun Technology Co., Ltd. to establish a soil environment monitoring system, which can real-time observe the changes of soil environment in vineyards. Hydra soil moisture, temperature and conductivity sensor can measure soil moisture, temperature and conductivity quickly and accurately. Hydra probe was used to measure these variables synchronously. Hydra probe was used to measure these variables synchronously. The sampling frequency was once every 30 minutes, soil moisture and salinity were collected directly. The data collected by the probe can directly convert into analog voltage and output as follows: real-time dielectric constant, soil salinity, soil conductivity, temperature-corrected soil conductivity and temperature-corrected soil moisture. Hydra sensor for soil moisture, temperature and electrical conductivity is connected with the data collector, and the data collector collect the data of soil moisture, temperature and electrical conductivity which measured by the sensor. These data can be sent back to the data center server wired or wireless.

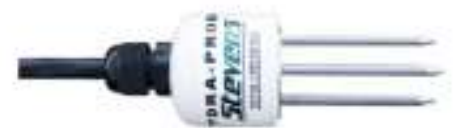

Fig.3: Hydra sensors for soil moisture, temperature and conductivity

\section{(2)Meteorological Monitoring Station}

Meteorological monitoring requires the ability to observe and record wind direction, wind speed, temperature, humidity, rainfall and its changes and illumination near the ground. This system uses MC-NQXZ meteorological monitor produced by Beijing Mengchuangweiye Technology Co., Ltd. to build farmland microclimate monitoring station. It records the wind direction, wind speed, temperature, humidity, rainfall and its changes outside and illumination conditions near the ground. The monitoring frequency is every 30 minutes. The collected data are uploaded to the remote storage of the Internet of Things platform in real time. The data can be viewed through mobile phones and computers at any time.

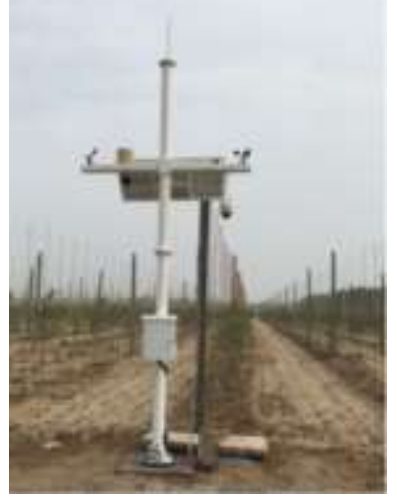

Fig.4: MC-NQXZ Meteorological Monitor 
(3) Groundwater level monitoring station

Groundwater level monitoring requires the observation and recording of water temperature, water level and other major water environmental indicators and their changes. This system uses the groundwater level monitoring equipment DATA-6216 and DATA-6218 produced by Tangshan Pingsheng Electronic Technology Development Co., Ltd. to establish the groundwater level monitoring station, real-time observation of water temperature and water level changes, and reserve interfaces to facilitate the expansion of other water environment monitoring indicators. The monitoring frequency is once every 30 minutes, and the data is transmitted back to the data center server.

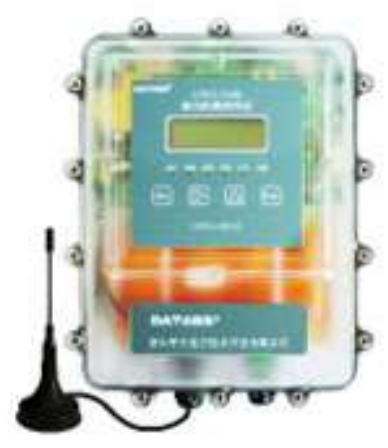

DATA-6216

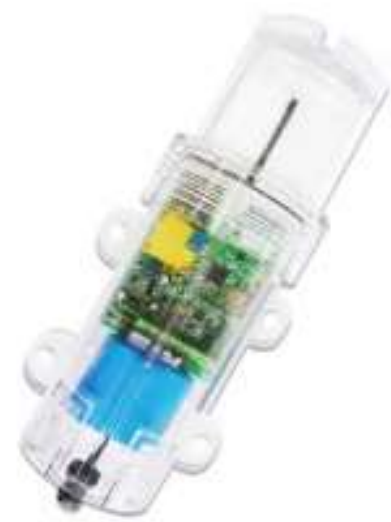

DATA-6218

Fig.5: Groundwater level monitoring equipment

(4) Air Quality Monitoring Station

The monitoring of particulate matter in vineyards requires that the concentration of particulate matter near the ground, negative oxygen ions, nitrogen oxides, sulfides and their changes can be observed and recorded. Particulate matter concentration can affect the growth of grapes and the health of tourists. This system uses JH-KQ miniature environmental air quality monitor produced by Jiangsu Jihua Electronic Technology Co., Ltd. to establish a set of air quality monitoring system in vineyard. It monitors PM2.5, $\mathrm{PM} 10, \mathrm{O}_{3}, \mathrm{CO}, \mathrm{SO}_{2}$ and $\mathrm{NO}_{2}$ in air in real time. The monitoring frequency is every 30 minutes, and the data is sent back to the data center server.

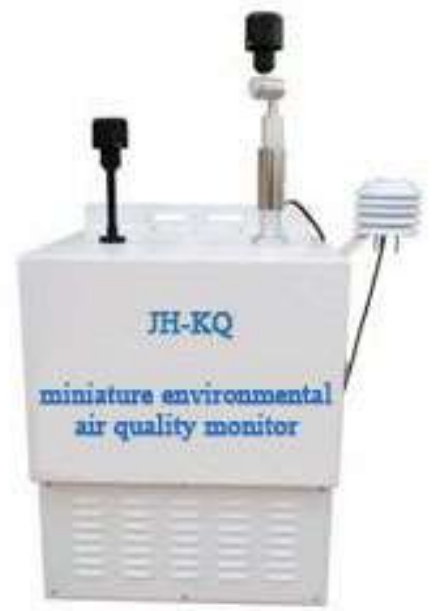

Fig.6: JH-KQ miniature environmental air quality monitor

\subsection{Layout scheme}

After comprehensive analysis, considering the current situation of the vineyard ecological environment in the eastern foot of Helan Mountains, the distribution of ecological monitoring sites in the vineyard in the eastern foot of Helan Mountains was determined, as shown in Figure 6. The layout scheme meets the needs of ecological environment monitoring of vineyards in the eastern foot of Helan Mountains. It can realize real-time collection, transmission, display and storage of ecological environment data of vineyards and provide data support for the construction of intelligent vineyards. 


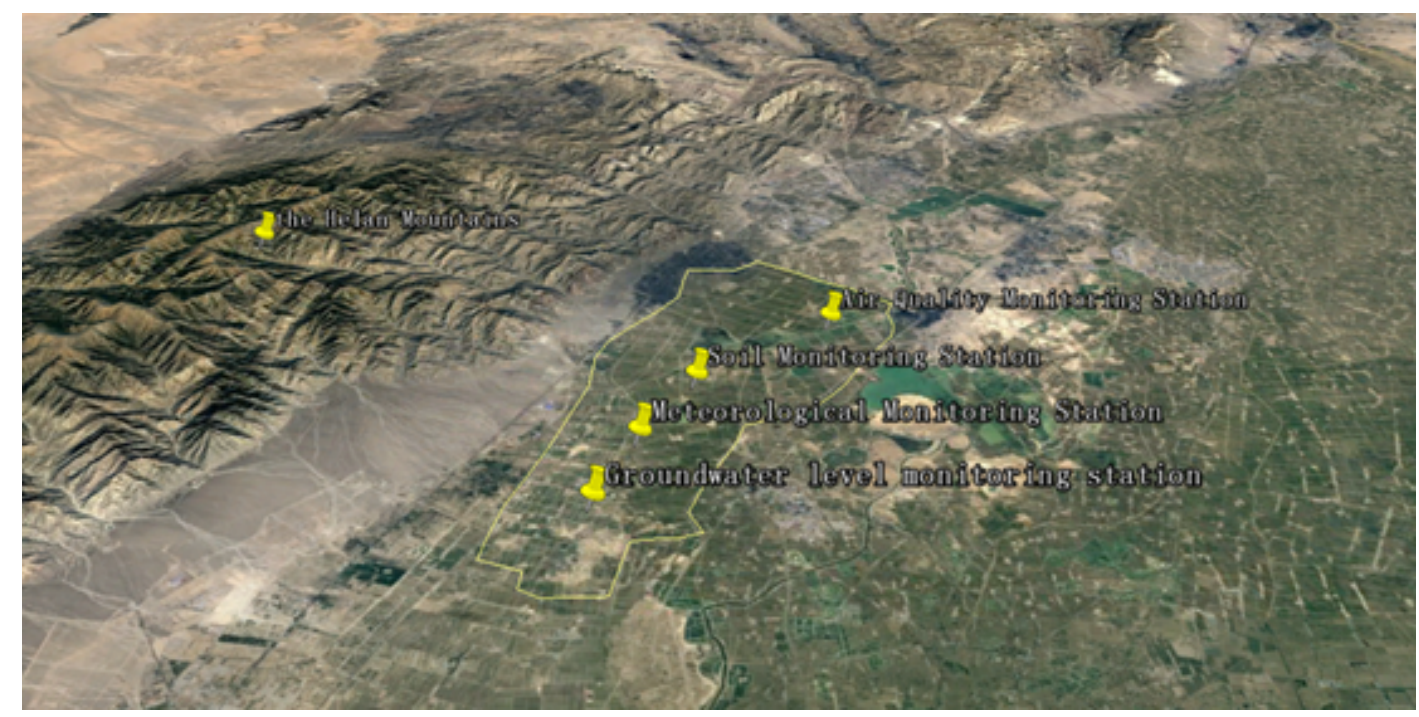

Fig 7: Layout of vineyard ecological environmental monitoring system

\subsection{Data Receiver and Publisher}

Monitoring station equipment and system platform support a variety of communication modes, such as 4G, GPRS, etc. Data is sent to monitoring platform through wireless sending module. Data is analyzed, pre-processed and stored in data center server by platform data receiving service. Cloud servers and cloud storage are used in data centers. Cloud servers provide data services and storage services respectively. After data upload, the server is responsible for parsing and storing the data in the database. The structure of the system login interface is shown in the following figure.

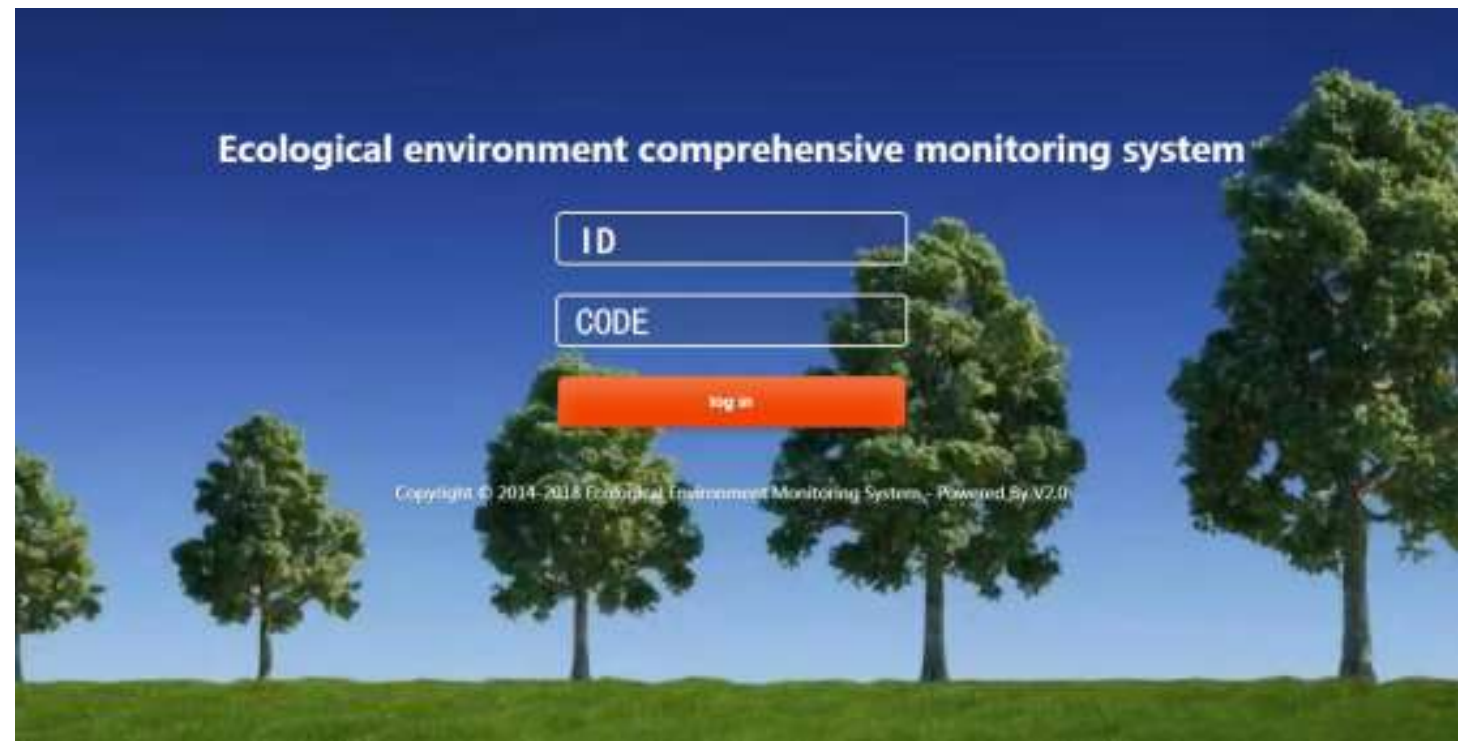

Fig.8: Login interface diagram of vineyard eco-environmental monitoring system based on wireless sensor network

\section{Conclusion}

Aiming at the actual needs of ecological environment monitoring of vineyards in the eastern foot of Helan Mountains, this paper presents the structure and design scheme of ecological environment monitoring system of vineyards in the eastern foot of Helan Mountains. This scheme based on wireless sensor network. It realizes the real-time monitoring, collection, transmission, display and storage of relevant information of four influencing factors such as soil condition, meteorological condition, groundwater level and particulate matter. It provides data support and technical support for the wisdom development of this region's grape industry. The whole system has the advantages of simple structure, low cost, easy installation and maintenance. It can be popularized and used with a little modification and has a good application prospect. 


\section{Acknowledgment}

This study was supported in part by the Trade-offs between Socio-Economic Development and Regional Ecological Security in Southwest China (Grant No. 2016YFC0502100).

This study was supported in part the CERNET Next Generation Internet Technology Innovation Project (Grant No. NGII20160317).

\section{Reference}

[1] ZHAO Shihua, SU Li. Opportunities, Challenges and Countermeasures for the Development of Ningxia Wine Industry [J]. Sino-overseas Grapevine \& Wine, 2016 (3): 60-62.

[2] Wang Wentao, Tengfei, Zhu Songli, et al. New thinking on China's green development strategy for Global Climate Governance [J]. China population resources and environment, 2018, 28 (07): 1-6.

[3] WANG Suyan, ZHANG Guangfen, Li Xin, et al. Effects of climate warming on heat resources and freezing injury of wine grapes in the eastern foot of Helan Mountain [J]. Acta Ecologica Sinica, 2017,37(11): 3776-3786.

[4] WANG Fenghua, ZHANG Shujuan. Research progress on Key Technologies of field information collection in precision agriculture [J]. Transactions of the Chinese Society of Agricultural Machinery, 2008, 39(5): 112-121.

[5] LI Wenchao, SUN Pan, WANG Zhenping. Effects of different soil conditions on physiology and fruit quality of wine grapes [J]. Journal of Fruit Science, 2012, 29 (05): 837-842.

[6] ZHANG Xiaoyu, LIU Yulan, ZHANG Lei, et al. Effects of meteorological conditions on some quality factors of wine grapes [J]. Chinese Journal of Agrometeorology, 2007 (03): 326-330.

[7] SHI Ming, ZHU Ying, SHI Haili, et al. Effects of irrigation on the growth, yield and quality of wine grapes in the eastern foot of Helan Mountain [J]. Water Saving Irrigation, 2013 (10): 1-3.

[8] LIU Yulan. Quality Index Analysis of Wine Grape and Its Relation with Meteorological Conditions [D]. Nanjing University of Information Engineering, 2006.

[9] WANG Lina, ZHANG Zhenwen. Study on the Fruit Quality of Wine Grapes in Ningxia Producing Area in 2009 [J]. Northern Horticulture, 2011 (03): 4-8.

[10] ZHAI Heng. Cultivation and Processing Technology of Wine-making Grape [M]. China Agricultural Publishing House, 2001:199-238.

[11] CHANG Xuzheng, KANG Yongyi, FANG Xiaoying. Brief discussion on the development prospects of wine grapes from the climatic resources of 222 regiment [J]. Xinjiang Farm Research of Science and Technology, 2002 (04): 20-22.

[12] ZHANG Xiaoyu, LIU Yulan, ZHANG Lei, et al. Effects of meteorological conditions on some quality factors of wine grapes [J]. Chinese Journal of Agrometeorology, 2007 (03): 326-330.

[13] LI Hua, HUO Xingsan. Water Indicators for Climatic Regionalization of Wine Grapes in China [J]. Chinese Journal of Ecology, 2006 (09): 1124-1128. 